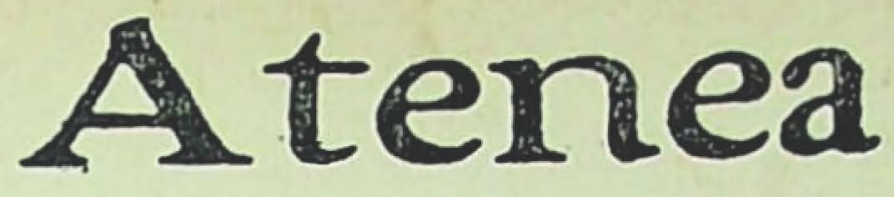

REVISTA MENSUAL DE CIENCIAS, LETRAS $Y$

ARTES. PUBLICADA POR LA

UNIVERSIDAD DE CONCEPCION.

Año VII - Santiago, Agosto de $1930-$ Núm. 66

Marta Brunet.

\title{
PLAZA DE MERCADO
}

7 A plaza es grande y cuadrada, con piso de finas piedrezuelas de río. Dos avenidas escriben una $\mathrm{X}$ bordeada de árboles en esta pizarra áspera. Las avenidas están soladas de adoquines. En el centro de la plaza hay una pileta de alto chorro, agua que cae diciendo una canción de gotas reidoras. Cuatro faroles montan guardia en torno a la pileta. En cada esquina de la plaza se yergue otro farol. Aun están encendidas las luces y como ya el amanecer se ha deslizado hasta la cumbre de la cordillera, estas luces tienen un triste color amarillento. Una ringla de casas anodinas corre a un costado de la plaza, más allá de la calzada y de la acera. Paralela hay otra ringla idéntica. Perpendicular una semejante. Al frente de ésta, entre las fachadas que se imitan servilmente, se alza el templo de la Merced, todo blanco, arquitectura noble, con las torres inconclu- 
sas y la imagen de la Virgen sobre el tímpano del peristilo, con su aureola de luces diminutas, aro de oro en torno a la cabeza divina.

Dos carabineros a caballo recorren la plaza dando órdenes estentóreas. Un empleado municipal lleva una prolija apuntación en unos papeles que el viento pone ariscos. Por las ocho boca-calles que desembocan en la plaza van llegando incesantemente las carretas que portan los productos que han de venderse en el mercado. Hay toda clase de vehículos, desde la carreta chancha que chirrea su primitivez hasta el camión automóvil de claxon estridente, desde el carrito de mano con toldo colorín hasta la carretela tirada por mulas, desde el antiguo coche de familia empingorotado sobre altas ruedas hasta la carreta emparvadora ancha de pasto recién talado. Todos los productos de la región riquísima van entrando lentamente por las ocho boca-calles en fila interminable. $Y$ van tomando colocación en el cuadrado que se llena de manchas obscuras, bullentes de actividad.

Desde el otro lado de la cordillera un niño travieso echa por el cielo el gran balón del sol, todo rojo, recién pintado por las manos del alba. Una luz creciente va barriendo las sombras hacia la costa para arrojarlas al mar. Los faroles cierran su pupila cansada y cada gota de agua en la pileta es un brillante iridiscente.

Con la luz del día hay un paro en la llegada de los vehículos. Pero ahora es un enjambre de gentes peatonas el que concurre el recinto de la plaza llevando canastos, cajones, burros y caballos de tiro, sobre los cuales se equilibran las árguenas desbordantes de verduras y frutas. Bajo los árboles que bordean la $\mathrm{X}$ hay pequeñas mesas entoldadas en cuya cubierta empiezan a colocarse las ventas de flores, de frutas, de cacharrós, de quesos, de legumbres. Más allá están las picanterías, las fritangas, los pequenes, las empa- 
nadas, el chocolate y los picarones. Luego los ponchos rabiosos de colorines hechos en Maule y los otros de dibujo indígena con no sé qué tristeza en su blanco y negro, las acioneras y las cinchas, los capachos de cuero y los estribos de madera lindamente trabajados; en seguida campean las gredas de Quinchamalí, deliciosas de primitivismo, negras, con grecas pintadas de rojo y amarillo: platos y cazuelas, fuentecillas y olletas, formas prácticas unidas a las otras fantásticas del animal del agua y la bestia dañina, especie de fauna antediluviana, cuerpos enormes sobre tres patas muy cortas, cuellos inconmensurables terminados en una cabeza chiquita, toda una serie destinada a alcancías, a juguetes de niños, a garrafas para agua y vino. Más allá aún están la hojalatería, los muebles y los canastos; otro lado lo ocupan la ropa hecha, los colchones, las frazadas de fino hilado, las lamas y los choapinos en que se muestra la tradición del telar araucano. En una esquina quedan las carretas con los productos de la montaña: carbón, leña, trigo, porotos, maíz, lentejas, papas, cebollas. Se oyen risas, gritos, órdenes, parlas torpes de montañeses, decires donairosos de gentes costinas, gracias picantes de los pueblerinos, cazurrerías de cerrucos matreros. Ya han llegado los compradores y la venta es un pequeño juego de pedir y regatear.

-Tres pesos la docena....

- Paños de Tomé a precios de fábrica...

-Rica l'aloja y barata....

-El específico para hacer salir pelo, el específico maravilloso. ¿Quién compra el específico maravilloso para hacer salir pelo?

-Recién tomados de la mata los tomates.... Los tomates fresquitos....

-Al queso de cabra....

-Todo a cuarenta.... Todo a cuarenta.... Caserita cómprame algo.... Todo a cuarenta.... 
- La rica sustancia de Chillán.... La sustancia que hace resucitar los muertos.... -La Discusión... cusión... cusión... El Día... . Día... Día...

-iAquí está Moyita haciendo picarones!

Cada frase es como una saeta ardiente que se clavara en la atmósfera aun pura de amanecer.

- Ya está, Periquito, sáquele la suerte a la señorita.

La caja del organillo tiene encima una pequeña jaula y desde ella miran con sus ojillos de brilloso azabache la dos caturritas verdes de cuello ceniciento y curvo pico sonrosado. Una de ellas toma un andar balanceado, lleno de comicidad, y avanza hasta salir de la jaula y coger en el plano delantero una hojita enrollada que con otras iguales están repartidas en cuatro grupos idénticos. Y con un chillido que parece una risa contenida, la caturrita entrega al hombre del organillo el papel que tiene en el pico. A su vez el hombre se lo entrega a la campesina ilusionada que allí espera encontrar en malos versos la suerte que el Destino le reserva en amores y en fortuna.

- ¿A quién se le ve la suerte? ¿A quién le sacan la suerte los periquitos sabios? ¿A quién? ¿A usted señorita? Páguese la chaucha.... ¿Casada o soltera? ¡Ya está, Periquito, sáquele la suerte a la señorita!

Cuando el público escasea, el hombre empieza a moler melodías en su organillo, viejas melodías que llegan al corazón removiendo polvo de añoranzas.

Más allá están los ciegos, con sus violines, tocando a trío un vals romántico, alta la cabeza, con las pupilas muertas orientadas al sol, mirando aquella claridad presentida que les pone en el alma un calor de reconfortamiento. Ahora uno de ellos canta con voz de plañideras notas:

Corazones partidos.

Alta en su carreta colonial, que tal vez fuera entonces orgullo de un bisabuelo de rancia prosapia, la 
meica yerbatera reparte su mercancías con un aire de bruja hacedora de ensalmos. Junto a ella hay todo un hacinamiento de figuras espectrales, caras tajadas de arrugas que buscan ansiosamente el medicamento prolongador de vida; cutis de cera, lívidos; manos de retorcidos dedos con uñas demoníacas; ojos lagrimeantes; piernas torpes que arrastran los pies reumáticos. Y junto a este agua fuerte de aquelarre por la deformidad monstruosa con que se anuncia la muerte, está la acuarela más patética aún de la juventud marcada de palidez y flacura, hoja en que sólo hay escrito un pase de la enfermedad para el gran viaje.

-Flores para la señorita.... A peso la docena de claveles.... Las rosas valen dos pesos....

Arden los claveles en apretados mazos y las hortensias rosadas, las azules y las blancas parecen globos, grandes esferas destinadas a las manecitas de un niño melancólico. Los lirios tardíos traídos de la montaña tienen un altivo erguirse de princesas medioevales. Las rosas aroman un perfume espeso que llega a ser una obsesión para el olfato. Rojo, azul, blanco, violeta. Y entre todos, la mancha áurea de los dedales de oro. Y detrás de las flores la otra gama violenta de colorido de las frutas, regalo para los sentidos que nos da nuestra tierra tendida perezosamente a lo largo de todos los climas.

-Y en dey.... ¿Qué más quería por un peso? ¿Un pajarito pa la mano tamién?

Es Moyita que se enfada. Hace años de años que está allí en su puesto, con el delantal blanco atado a la cintura, detrás del fogón en que hay una olleta de negro barro en que con un rápido movimiento de la cuchara va friendo los picarones. Al lado está su mujer, doña Chumi, con los brazos desnudos hasta el codo, muy blanco el delantalón, con un pañuelo atado a la cabeza y la sonrisa bailándole en los ojazos de chaquira negra a la par que le taja la cara con la blancura 
de los dientes espléndidos. Moyita trabaja. Con la cuchara toma la masa de la batea y trazando un semicírculo cae esta en la grasa chirriante. ¿Cuántos minutos son necesarios para que el picarón esté en su punto? Es el secreto de Moyita que los cuenta a su modo, tiempo en que la masa se esponja, se dora. Otro movimiento de la cuchara hace que. la fritura se dé vuelta. Y cuando este lado se esponja y dora a su vez, Moyita toma un largo palo puntudo y ensartando la golosina por el hoyo que tiene al centro, la coloca rápido y triunfal en el platillo en que ha de servirse. Entonces es el momento en que Mechunga-la hijaentre en acción. Mechunga tiene carita redonda color de greda, ojos verdes largos y sesgados, tupición de pestañas, barra firme en las cejas, nariz que husmea los vientos, boca gruesa, pulposa de sensualidad ysobre todo-la sal y el ají de la malicia que le retoza en el cuerpo y que para cada cual tiene la respuesta polola y la sonrisa taimada. Es ella quien termina la pequeña obra maestra de Moyita: ella quien vierte sobre el picarón puesto en el platillo el almíbar de chancaca que ha de endulzarlo.

Pero hay ahora delante de Mechunga una vieja que no entiende de seducciones y que regatea el precio de la golosina. Y Moyita dice desde lo alto de su maestría: -Los picarones de Moyita tienen su precio y su fama

Y Mechunga agrega:

-Es que la... veterana cree entoavía que estamos en la época del cinco....

Pasan dos monjas vestidas de negro con las cornetas albas haciendo marco a las caritas de cándida expresión. Una de ellas lleva un gran cesto: la otra un Niño Dios en el pesebre, metidito en una urna de cristales con una alcancía abajo. Quién da una chaucha, quién un atado de perejil, quién dice una cuchufleta, quién averigua noticias modosamente de una amiga que está 
en la casa correccional que las monjas mantienen. Todo para ellas es bienvenido y lo mismo dicen: "Dios lo bendiga, hermano» al que dijo la maldición que al que preguntó afablemente; al que dió su limosna que al que se negó con una grosería.

- Se lo llevo, patroncita.... Le llevamos los paquetes, patroncita....

Las árguenas desbordan verduras y el carbón deja manchones negruzcos al vaciarse los sacos. Una era de maíz volcada en el suelo deslumbra los ojos como en la trilla clásica. El espejo de un lavatorio lanza un reflejo de sol enceguecedor. Por el aire vuela una bandada de palomas y otra bandada de horas vuela desde el campanario dando las siete. Luego hay un grave repique de campanas que llaman a misa.

¿Dónde estamos? ¿Es el mercado de una vieja ciudad española? Un zoco? ¿Un rastro? ¿Una lonja? ¿La plaza de la Fuentina? No, es un tipico rincón chileno, la plaza de la Merced en esta ciudad mía de Chillán, muestra eso sí de nuestro entronque en Iberia. Continúa en ella la tradición y los años no le han restado ni colorido ni pintoresco ni originalidad.

Castiza levadura en la harina de nuestro pan criollo. Sabor único que bien aprecian los buscadores de belleza en este Chile inexplorado que somos. 